\title{
Macroeconomic Variables as Common Pervasive Risk Factors and Empirical Content of the Arbitrage Pricing Theory in Pakistan
}

\author{
Ali Ataullah*
}

\begin{abstract}
The Arbitrage Pricing Theory (APT) of Ross [1976] is one of the most important building blocks of modern asset pricing theory, and the prime alternative to the celebrated Capital Asset Pricing Mode1 (CAPM) of Sharpe [1964], Lintner [1965], and others. This paper briefly reviews the theoretical underpinnings underlying the APT and highlights the econometric techniques used to test the APT with pre-specified macroeconomic factors. Besides this, the prime objective of this study is to perform an empirical test of the APT in the Pakistani stock market by using pre-specified macroeconomic factors and employing Iterative NonLinear Seemingly Unrelated Regressions (ITNLSUR). These empirical results will be, hopefully, helpful for corporate managers undertaking cost of capital calculations, for domestic and international fund managers making investment decisions and, amongst others, for individual investors who wish to assess the performance of managed funds.
\end{abstract}

\section{The Arbitrage Pricing Theory - A Review}

\subsection{The Theory}

After a number of theoretical, as well as, empirical failures of $\mathrm{CAPM}^{1}$, Ross [op cit.] presents the APT as a testable alternative to the CAPM. Roll and Ross [1980] note that the popularity of the CAPM is based much less on its theoretical underpinnings than upon the intuitive descriptions that surround it. The basic argument behind the CAPM is that in a well functioning capital market, investors must be rewarded for assuming risks. In other words, to induce an investor to hold risky assets instead of riskless assets, like treasury bills, she or he must be promised a higher return than that of riskless assets. The CAPM assumes that the asset's

\footnotetext{
* The author is currently a lecturer in Economics and Finance at The Hamdard University, Pakistan.

Acknowledgement: I would like to thank Minh Hang Le for helpful comments and discussion on an earlier version of this paper. Any remaining errors are the author's responsibility.

${ }^{1}$ See, for example, Roll[1977] for theoretical shortcomings of CAPM.
} 
returns are linearly related to a single common factor - the rate of return on the market portfolio. The APT is based on similar intuition but is much more general because it assumes that the random returns of each security is a linear combination of a small number of common, or pervasive, factors, plus an asset specific random term. Mathematically ${ }^{2}$;

$$
\widetilde{R}_{i}=E\left(\widetilde{R}_{i}\right)+\beta_{i 1} \widetilde{F}_{1}+\ldots \ldots \ldots . . .+\beta_{i k} \widetilde{F}_{k}+\widetilde{\varepsilon}_{i}
$$

where

$\widetilde{R}_{i}$ is the random rate of return on the $i$ th asset,

$E\left(\tilde{R}_{i}\right)$ is the expected rate of return on the $i$ th asset,

$\beta_{i k}$ is the sensitivity of the $i$ th asset's returns to the $k$ th common factor,

$\tilde{F}_{k}$ is the mean zero $k$ th factor common to the returns of all assets under consideration, and

$\widetilde{\varepsilon}_{i}$ is white noise that represents the asset specific risk or idiosyncratic risk associated with the $i$ th asset.

In this kind of factor mode1, it is assumed that there are $k$ systematic factors that are mainly responsible for the movements in the assets' returns. These factors are common to all assets; the components of return due to unsystematic factors such as firm-specific or industry events are represented by the idiosyncratic term.

The APT is derived under the following assumptions ${ }^{3}$ :

1. Asset markets are perfectly competitive and frictionless;

2. All investors have homogenous beliefs;

3. Investors have monotonically increasing concave utility function;

4. The number of assets existing in the capital markets from which portfolios are formed is much larger than the number of factors i.e. $n>k$.

Given the above set of assumptions and with an additional noarbitrage restriction, in equilibrium all the portfolios that can be selected

${ }^{2}$ CAPM could be viewed as a special case of APT.

${ }^{3}$ For a complete set of assumptions and derivation of the APT, see Ross (1976). 
from among the set of assets under consideration and that satisfy the conditions of (a) using no wealth and (b) and having no risk must earn no return on average. These portfolios that require no change in wealth are called arbitrage portfolios ${ }^{4}$. Mathematically, the zero change in wealth is written as:

$$
\sum_{i=1}^{n} w_{i}=0
$$

If there are $\mathrm{n}$ assets in the arbitrage portfolio, then the additional portfolio return gained is:

$$
\begin{aligned}
& \widetilde{R}_{p}=\sum_{i=1}^{n} w_{i} \widetilde{R}_{i} \\
& \widetilde{R}_{p}=\sum_{i} w_{i} E\left(\tilde{R}_{i}\right)+\sum_{i} w_{i} \beta_{i 1} \widetilde{F}_{1}+\ldots \ldots \ldots \ldots+\sum_{i} w_{i} \beta_{i k} \widetilde{F}_{k}+\sum_{i} w_{i} \tilde{\varepsilon}
\end{aligned}
$$

Now,

1) Selecting percentage change in investment ratios that are small;

2) Diversifying across a large number of assets (this eliminates the idiosyncratic risk); and

3) Choosing weights, $w_{i}$, so that for each factor, $k$, the weighted sum of the systematic risk component, $\beta_{i k}$, approaches to zero.

Thus equation (1.3) becomes

$$
\tilde{R}_{p}=\sum_{i} w_{i} E\left(\tilde{R}_{i}\right)
$$

The arbitrage portfolio, so constructed, has no risk (either systematic or unsystematic) and requires no new wealth. If the return on the arbitrage portfolio were not zero, then it would be possible to achieve an infinite rate of return with no capital requirement and no risk. But, as mentioned earlier, the derivation of the APT assumes the capital markets to be in equilibrium, and such an opportunity to obtain infinite returns without any risk and investment is not possible if the capital market is to be in equilibrium. Therefore, the equation (1.4) becomes:

\footnotetext{
${ }^{4}$ To form a portfolio that requires no wealth, one may short sell some assets or sell some already held assets and use the proceeds to buy other assets.
} 


$$
\tilde{R}_{p}=\sum_{i} w_{i} E\left(\tilde{R}_{i}\right)=0
$$

Ross [1976] shows that the algebraic consequences of the above equations is that the expected return vector must be a linear combination of the constant vector and the coefficient vectors. Algebraically, there must exist a set of $\mathrm{k}+1$ coefficients, $\lambda_{0}, \lambda_{1}, \ldots, \lambda_{\mathrm{k}}$ such that

$$
E\left(\tilde{R}_{i}\right)=\lambda_{0}+\lambda_{1} \beta_{i 1}+\ldots \ldots . .+\lambda_{k} \beta_{i k}
$$

where $\lambda_{k}$ is the risk premium required by an investor per unit of risk due to unexpected shocks in the kth factor, and if there is a riskless asset with a riskless rate of return, $R_{f}$, then its sensitivity to the shocks in common factors would be $\beta_{0 k}$ and, we can write $\mathrm{R}_{\mathrm{f}}=\lambda_{0}$. By substituting equation (1.6) into equation (1.1)

$$
\widetilde{R}_{i}=R_{f}+\beta_{i 1}\left(\tilde{F}_{1}+\lambda_{1}\right) \ldots \ldots \ldots+\beta_{i k}\left(\tilde{F}_{k}+\lambda_{k}\right)+\widetilde{\varepsilon}_{i}
$$

or in excess returns form

$$
\tilde{R}_{i}-R_{f}=\beta_{i 1}\left(\tilde{F}_{1}+\lambda_{1}\right) \ldots \ldots \ldots+\beta_{i k}\left(\tilde{F}_{k}+\lambda_{k}\right)+\widetilde{\varepsilon}
$$

The arbitrage pricing theory is much more robust than the capital asset pricing model for several reasons:

1. The APT makes no assumption about the empirical distribution of assets returns.

2. The APT makes no strong assumption about individuals' utility functions (at least nothing stronger than non-satiation and risk aversion).

3. Unlike the CAPM, the APT takes into account the effect of many common factors on assets' returns.

4. There is no special role of market portfolio in the APT.

\subsection{The Empirical Tests of the AP}

Although unlike the CAPM, the empirical test of the APT does not require market portfolio, but one important and rather difficult issue in the empirical tests of the APT is to find out the pervasive risk factors. Several methodologies have been adopted in this regard, for example, 
factor analysis, pre-specified macroeconomic factors, factor mimicking portfolios, etc. As the prime objective of this paper is to test the APT in Pakistan with pre-specified macroeconomic factors, this paper will only briefly discuss the empirical tests of the APT with pre-specified macroeconomic factors ${ }^{5}$.

\subsubsection{The APT and Pre-specified Macroeconomic Factors}

The fact that macroeconomic factors influence the stock market is well documented. For example, celebrated literature, like Lintner [1976], Modigliani and Cohn [1979], Chen, Roll, and Ross [1986], Fama [1981], and Antoniou et a1. [1998], has focused on the impact of various macroeconomic variables on stock returns. The idea of using macroeconomic variables as proxies for the pervasive risk factors is very intuitive, as it makes sense to say that there is a co-movement between assets' returns and some economy wide factor, say, inflation. Although the statistical methods, like factor analysis, help to test the validity of the APT, but they offer little in the way of economic intuition when attempting to interpret the estimated risk premia [Priestley, 1996, pp. 870]. Starting with Chen, Roll, and Ross [1986], the researchers have been specifying, ex ante, a set of macroeconomic variables as the proxies for common pervasive risk factors in the APT framework. But how should one specify, ex ante, the macroeconomic factors that [may] have some relationship with assets' returns? To specify macroeconomic variables that may affect the stock returns, the researchers have utilised the traditional dividend discount model. These studies assume that stock prices ' $p$ ' can be written as the expected discounted dividends:

$$
p=\frac{E(d)}{r}
$$

Where ' $d$ ' is the dividend stream, ' $r$ ' is the discount rate, and $E($.) is the expectation operator. The above expression suggests that any economic variable that influenced the expected dividend stream or the discount factor would, in turn, affect the stock prices. Using this framework, many economy wide variables could be used as proxies of pervasive factors.

\subsection{2 - Estimation of Factor Risk Premia}

Another crucial issue in obtaining risk premia associated with macroeconomic factors is the methodology applied to test the APT. A vast number of techniques have been applied to test the multifactor APT. This

\footnotetext{
${ }^{5}$ For a detailed review of empirical tests of the APT, see Connor and Korajczyk [1995].
} 
section presents a critical review of two of the most important methodologies i.e. two-step methodology and non-linear seemingly unrelated regression (NLSUR), which are used to obtain risk prices associated with pre-specified macroeconomic factors.

\section{Two-Step Methodology:}

The early focus of this cross-sectional methodology was to test the single factor model i.e. the CAPM [see, for example, Fama and Macbeth, 1973], but for the last two decades this methodology has been widely used to estimate the factor risk premia and asset sensitivities in the APT framework. In the first step of this approach, the estimates of true assets' sensitivities are obtained by using the following regression:

$$
R_{i t}-R_{f t}=\alpha_{i}+\sum_{k=1}^{K} \beta_{i k} f_{k}+\varepsilon_{i}
$$

Where ' $R_{i t}$ ' is the vector of returns on the ith asset [portfolio] at time ' $t$ ', $\alpha_{i}$ is the constant, ' $\beta_{i k}$ ' is the ith asset's [portfolio's] sensitivity to the kth factor, ' $\mathrm{R}_{\mathrm{ft}}$ ' is the risk free return, and $\varepsilon_{\mathrm{i}}$ is the error term. In the second step, these estimates ' $\beta_{i k}$ ' of true betas are used as independent variables to obtain the estimates of factor risk premia. Mathematically;

$$
R_{i t}-R_{f t}=\gamma_{i}+\sum_{k=1}^{K} \lambda_{k} \hat{\beta}_{i k}+v_{i}
$$

In case of the CAPM, the term $\sum_{k=1}^{K} \beta_{i k} f_{k}$ is replaced by $\beta_{i} R_{m}$ ', where ' $\mathrm{R}_{m}$ ' is return on market portfolio. In the tests of the CAPM with two-step methodology, market index could be used as a proxy for the market portfolio [but, see also Roll, 1977, on market index as a proxy for the market portfolio]. On the other hand, there is no clear proxy for the common factors in the case of the APT. The early tests of the APT use factor analysis, principle components, or some variant to find out the common factors ${ }^{6}$. Starting from Chen, Roll, and Ross [1986], the researchers have been using pre-specified macroeconomic factors as a proxy for common risk factors. Some of the important studies that apply two-step methodology to estimate risk prices and assets' sensitivities with pre-specified macroeconomic factors are Chen, Roll, and Ross [1986], Chan, Chen, and Hsieh [1985], Ferson and Harvey [1991], Warga [1989], and Clare and Thomas [1994]. The overall conclusion of these studies is that there are a number of economy wide factors, like unanticipated inflation, industrial

\footnotetext{
${ }^{6}$ See, for example, Gehr [1978] or Roll and Ross [1980].
} 
production, term structure, default risk etc., that carry a significant price of risk.

\section{Problems with two-step methodology}

\section{a-Contemporaneous Correlation}

The traditional two-step methodology is usually undertaken using Ordinary Least Squares (OLS) ${ }^{7}$. One of the essential conditions for the efficiency (minimum variance) of the OLS estimates is that there is no contemporaneous correlation between idiosyncratic returns $[\mathrm{see}$, for example, Greene, 2000, pp.580-601]. Mathematically;

$$
\operatorname{Cov}\left(\varepsilon_{i} \varepsilon_{j}\right)=0 \quad \text { for all } \mathbf{i} \neq \mathbf{j}
$$

Where ' $\varepsilon$ ' is the error term from equation (1.10). If this condition does not hold, then, the resultant estimates of betas (the independent variables in the second step) will be inefficient and the associated standard error will be biased upward [Clare et a1., 1998, pp. 1213]. But studies, like Connor and Korajczyk [1993, pp.1264], suggest that in reality there is a possibility of contemporaneous correlation. Therefore, the conclusion based on the two-step methodology, which does not accommodate contemporaneous correlation, will not be reliable.

\section{b-Portfolio Formation \& Errors-In-Variables (EIV)}

The empirical tests that apply two-step methodology use portfolios instead of individual assets in the estimation process. One purpose of using portfolios in the two-step methodology is to eliminate the diversifiable risk [Clare and Thomas, 1994, pp. 317]. The second, and rather more important reason behind using the portfolios is to reduce the EIV problem [see, for example, Shanken, 1992]. The EIV problem occurs because in the second step, instead of using the true betas, the estimates of betas are used as independent variables. The empirical tests, like Friend and Blume [1970], of the two parameter model suggest that the betas of portfolios can be estimated more precisely than those of individual assets. Therefore, we

\footnotetext{
${ }^{7}$ See, for example, Chen et al. [1986].Some studies like Litzenberger and Ramaswamy [1979] also apply Weighted Least Squares and (WLS) or Generalised Least Squares (GLS). But, as Shanken [1992] suggests, these are not true WLS or GLS because the true covariance matrix or the error term is rarely known.
} 
should use the portfolios rather than individual assets in the two-step methodology ${ }^{8}$.

The EIV problem can be reduced, if not eliminated, by using the portfolios in the estimation process. But, the portfolio formation is a problem in itself as there are different techniques for forming portfolios. For example, beta sorted portfolios [see, for example, Fama and Macbeth, 1973], size sorted portfolios [see, for example, Chen, Roll, and Ross, 1986] or size based portfolios at the beginning of each year using asset returns of subsequent years [see Shanken and Weinstein, 1990]. The results of the APT are sensitive to the portfolio formation technique used, and there is an ambiguity about which technique to apply to form the portfolios [see, Clare and Thomas, 1994].

Given that the two-step methodology faces many problems, there is a need for a technique that avoids these problems. One such technique to estimate the factor risk premia in the APT framework is the use of NonLinear Seemingly Unrelated Regressions (NLSUR) ${ }^{9}$.

\section{Non-Linear Seemingly Unrelated Regressions (NLSUR)}

One important issue in the tests of the APT is the factor structure i.e. the form that the covariance matrix for the idiosyncratic returns takes. Ross [1976] uses strict factor structure (no contemporaneous correlation) in the derivation of the APT. Chamberlain [1983] and Chamberlain and Rothschild [1983] develop an asymptotical model, called approximate factor structure, which allows the non-diagonality in the covariance matrix of error terms. If the error covariance matrix follows an approximate factor structure but we impose strict factor structure, then too many factors may be identified [see, Trzcinka, 1986]. Therefore, it is crucial to explicitly allow for the approximate factor structure. Given an error covariance matrix structure that recognises contemporaneous correlation between the idiosyncratic returns, what we desire is a statistical model that will accommodate the approximate factor structure. One such methodology is the use of Zellner's[1962] seemingly unrelated regressions methodology that is extended by Gallant[1975] to accommodate the non-linearity in the models. Following Gallant [1975], Burmeister and McElroy $[1985,1988]$ use the NLSUR approach to jointly estimate the assets' sensitivities and risk premia attached to pre-specified macroeconomic factors in the APT

${ }^{8}$ Also see, Litzenberger and Ramasway [1979] and Davidson and McKinnon [1993, section 7.2] for further details on EIV.

${ }^{9}$ Recently, this method has also been used to test the single factor model i.e. CAPM. See for example, Clare et al. [1998]. 
framework. Following are the advantages of this methodology over the traditional two-step methodology:

1. As the sensitivities and risk premia are estimated jointly, the EIV problem does not occur because we do not need to use the estimates of some true value as the independent variable.

2. As there is no EIV problem, there is as such no need to form portfolios and we can avoid the problem of selecting a particular portfolio formation technique.

3. This framework can be used to test, rather than impose, the restriction that APT imposes on the linear factor model [Antoniou et a1., 1998, pp. 225].

4. When market portfolio is used as a pre-specified factor, then it should not be treated as an exogenous variable because the proxy used for the market portfolio is usually the market index, which is composed of similar securities that we use as exogenous variables i.e. returns on individual assets $^{10}$. The NLSUR framework could be extended to non-linear three stage least squares (NL3SLS), which use simultaneous equation models and, therefore, accommodate the endogeniety of the market portfolio.

Due to the above advantages, this paper will employ an extension of NLSUR i.e. Iterative Non-Linear Seemingly Unrelated Regression (ITNLSUR), to estimate the risk premia associated with macroeconomic factors of Pakistan.

\section{The Common Risk Factors for Pakistan}

As mentioned in section 1 , asset prices are commonly believed to react sensitively to the macroeconomic factors of the economy, which implies that there is systematic risk entailed by some economy wide factors. There are many studies that determine the risk price attached to macroeconomic factors of developed and less developed countries, for example, Chen, Roll, and Ross [1986] for the USA, Antoniou et a1.[1998] for the UK, Priestley and Clare [1998] for Malaysia, and Brown and Otsuki [1990] for Japan. But in the author's knowledge, there is no study that determines the risk premia associated with the macroeconomic factors of Pakistan. By employing ITNLSUR estimation, this section will use the APT framework to find the risk premia associated with the macroeconomic factors of Pakistan.

\footnotetext{
${ }^{10}$ See Burmeister and McElroy [1988] for more on endogeneity of market portfolio.
} 


\subsection{Specification of Macroeconomic Variables}

As mentioned earlier, the search for the potential sources of systematic risk for the APT usually starts with an evaluation of the traditional dividend discount model. While this approach opens up a plethora of possible candidates for systematic risk factors, we can use the evidence from previous tests of the APT for potential candidates. Most of the macroeconomic factors used in this paper are the same as those used by Chen et a1.[1986] and Clare and Thomas[1994] (some of their macroeconomic variables are not used here due to non-availability of data for Pakistan). Table 2.1 presents the macroeconomic variables used as proxy for pervasive factors. Some of these macroeconomic variables are not used in the previous studies e.g. raw material prices, and domestic credit. These variables are used in this study because we believe that they may affect the discount rate in the dividend discount model i.e. equation (1.9). For example, an increase in domestic credit may be due to high demand of domestic credit, which may lead to an increase in domestic interest rates, and in turn an increase in discount rate, similarly an increase (decrease) in raw material prices could affect the revenue of firms that, in turn, would lead to a decrease (increase) in dividends.

Table-2.1: Macroeconomic Variables Used as Pervasive Risk Factors

Unexpected Inflation (Change in the log of Consumer Price Index(CPI))

Money Supply $\quad$ M1 in Banking Survey (MS)

Term Structure Yield on long-term bond minus yield on shortterm bonds.(TRM)

Exchange Rate Pak Rupee to US\$ rate (Market Rate)(EXC).

Industrial Production Substituted by Manufacturing Production.(MP)

Domestic Credit Domestic Credit (DCR)

Oil Prices World Oil Prices (OP)

Raw Material Raw Material Price Index (WPI)

Trade Balance $\quad$ Visible Trade Balance (TB) 


\subsection{Data}

The data for the above macroeconomic factors and for seventy randomly selected ${ }^{11}$ securities listed in the Karachi Stock Exchange is monthly, covering the period April 1993 to December 1998. The data on all the macroeconomic factors (reported by OECD, IFC or IMF data series), and securities is obtained from Datastream International, UK. The excess returns on securities are calculated by subtracting one-month Treasury bill rate from each security's returns.

\subsection{Unanticipated Shocks in Pervasive Factors}

The empirical tests of APT with pre-specified macroeconomic variables, use unanticipated shocks or surprises in the macroeconomic variables, because the anticipated changes in the common macroeconomic factors are already included in the prices of securities and all the risk is due to unanticipated shocks. To date, three techniques have been employed to generate surprises in macroeconomic factors ${ }^{12}$ :

a) The Rate of Change approach;

b) The Autoregressive (AR) and Autoregressive Integrated MovingAverage (ARIMA) approach; and

c) The Kalman-Filter approach.

In this paper, twelfth order AR model is employed to generate the surprises in the macroeconomic variables. The autoregressive (AR) approach assumes that investors forecast or make future expectations about macroeconomic variables, and use the AR technique to model these expectations. The residuals from these models are the surprises or unanticipated shocks to the particular variable. In the case of the AR approach, the time-series of macroeconomic variable is modelled as twelfthorder autoregressive process, and the residuals from the parsimonious version of this AR process are used as surprises [see, for example, Clare and

\footnotetext{
${ }^{11}$ Antoniou et al. [1998, pp.227] suggest that selecting securities in this manner raises the issue of survivorship bias which may make the estimated prices of risk conservative [see Greene, 2000, section 20.4, pp.927 for more on survivorship bias]. This problem can be avoided be forming portfolios of the stock. But, as mentioned in section 1, we do not know which method of portfolio formation is the best and the empirical results are vulnerable to the criteria of portfolio formation [see, for example, Clare and Thomas, 1994].

${ }^{12}$ See Priestley [1996] for the details and consequences of the use of different approaches to generate surprises.
} 
Thomas, 1994]. The results of the parsimonious version of AR model, along with F-test and $\chi^{2}$ values are presented in table 2.2. $\chi^{2}$ values are BrauchGodfrey (BG) test to check for first order autocorrelation in the residuals, and F-values test for the restrictions that insignificant lags are equal to zero. The results show that all the restrictions are easily accepted at $10 \%$ or lower level of significance, and the residuals are serially uncorrelated at $10 \%$ or lower level of significance, and therefore can enter as unanticipated shocks in APT estimation.

\section{Empirical Content of the APT in Pakistani Stock Market}

\subsection{Specification of the APT as NLSUR}

In the approximate factor structure, the error covariance matrix $\Sigma$ can be written as:

$$
\sum=E\left(\varepsilon \varepsilon^{\prime}\right)=\left(\begin{array}{cccccc}
E\left(\varepsilon_{1} \varepsilon_{1}^{\prime}\right) & E\left(\varepsilon_{1} \varepsilon_{2}^{\prime}\right) & \cdot & \cdot & \cdot & E\left(\varepsilon_{1} \varepsilon_{n}^{\prime}\right) \\
E\left(\varepsilon_{2} \varepsilon_{1}^{\prime}\right) & E\left(\varepsilon_{2} \varepsilon_{2}^{\prime}\right) & \cdot & \cdot & \cdot & E\left(\varepsilon_{2} \varepsilon_{n}^{\prime}\right) \\
\cdot & \cdot & & & \cdot \\
\cdot & \cdot & & & \cdot \\
\cdot & \cdot & & & & \cdot \\
E\left(\varepsilon_{n} \varepsilon_{1}^{\prime}\right) & E\left(\varepsilon_{n} \varepsilon_{2}^{\prime}\right) & \cdot & \cdot & E\left(\varepsilon_{n} \varepsilon_{n}^{\prime}\right)
\end{array}\right)
$$


Table-2.2: Parsimonious version of AR models for Macroeconomic Factors

1-Industrial Production(IP):

$$
\begin{aligned}
& \Delta I P_{t}=0.001420+0.13584 \Delta I P_{t-2}+0.16439 \Delta I P_{t-3}+0.200149 \Delta I P_{t-8} \\
& \begin{array}{llll}
(0.0005)^{* * *} & (0.078355) & (0.07842) & (0.07824)
\end{array} \\
& \chi^{2}=0.3878^{\#}
\end{aligned}
$$

2-Money Supply(MS):

$$
\begin{array}{rl}
\Delta M S_{t} & =\underset{ }{(0.00043)} \\
0.00072 & 0.55557 \Delta M S_{t-1}
\end{array}+\underset{0.06799)}{0.25302 \Delta M S_{t-3}}
$$

3- Domestic Credit(DCR):

$$
\begin{aligned}
& \Delta D C R_{t}=0.0001-0.36913 \Delta D C R_{t-1}-0.15451 \Delta D C R_{t-2} \\
& \text { (0.0002) (0.08074) } \\
& \chi^{2}=1.0967^{\#}
\end{aligned}
$$

4- Inflation (CPI):

$$
\begin{gathered}
\Delta C P I_{t}=\underset{(0.0003)}{0.000448} \\
\chi^{2}=3.9171^{\#}
\end{gathered} \quad+\begin{gathered}
0.34039 \Delta C P I_{t-1} \\
(0.0729)
\end{gathered} \quad 0.11812 \underset{(0.0762)}{\Delta C P I_{t-5}}+\underset{(0.07570)}{0.17125 \Delta C P I_{t-7}}
$$

5- Term Structure (TRM):

$$
\begin{array}{ccc}
\Delta T R M_{t} & =\underset{(0.00025)}{-0.000003} \\
\chi^{2} & =5.2310^{\#}
\end{array}+\underset{(0.08078)}{0.09448 \Delta T R M_{t-1}}+\begin{gathered}
0.16788 \Delta T R M_{t-12} \\
(0.0772)
\end{gathered}
$$

6-Oil Prices (OIL):

$$
\begin{gathered}
\Delta O I_{t}=\underset{(0.16)}{0.00154} \\
\chi^{2}=4.7844^{\#}
\end{gathered}+\underset{(0.08168)}{0.15297} \Delta \mathrm{OIL}_{t-6}
$$

7- Trade Balance(TRB):

$$
\begin{aligned}
\Delta T R B_{t} & =\underset{(0.006)}{0.0204}+\underset{(0.0670)}{0.5598 \Delta T R B_{t-1}}+\underset{(0.0692)}{0.2688 \Delta T R B_{t-3}}+0.1455 \Delta \operatorname{TRB}_{t-11} \\
\chi^{2} & =4.6538^{\#}
\end{aligned}
$$

8-Exchaneg Rates(EXC):

$$
\begin{array}{ccc}
\Delta E X C_{t} & =0.00233 \\
& (0.0017) & 0.1004 \Delta E X C_{t-10}+0.76643 \Delta E X C_{t-12} \\
\chi^{2} & =0.8084^{\#}
\end{array}
$$

9-Raw Material (RAW):

$$
\begin{aligned}
& \Delta R A W_{t}=0.00134-0.35207 \Delta R A W_{t-1}+0.2199 \Delta R A W_{t-5}+0.1331 \Delta R A W_{t-8} \\
& (0.0007)^{* * *} \quad(0.0725) \quad(0.0676) \\
& \chi^{2}=1.5746^{\#}
\end{aligned}
$$

a) \# denotes BG test where critical values of $\chi 2$ are 6.634, 3.841 , and 2.705 at $1 \%, 5 \%$ and $10 \%$ level of significance respectively. If the computed value is greater than the critical value, then the residuals are autocorrelated and vice versa. 
b) ** denotes that figures in parenthesis are standard errors

Unlike the strict factor structure, the above covariance matrix assumes that the non-diagonal terms could be non-zero [see, for example, Greene 2000, pp.595-603]. Rewriting equation (1.1), the T equations for ith security are given by [see, Burmeister and McElroy, 1985, for further details]:

$$
\begin{aligned}
& R_{i}=\lambda_{o} l_{T}+\sum_{k=1}^{K}\left(\lambda_{k} l_{T}+\tilde{f}_{k}\right) \beta_{i k}+\varepsilon_{i} \\
& R_{i}=\lambda_{o} l_{T}+X(\lambda) B_{i}+\varepsilon_{i}
\end{aligned}
$$

Where;

$$
\begin{aligned}
& \mathrm{l}_{\mathrm{T}} \text { is a } \mathrm{T} \text { vector of ones; } \\
& R_{i}=\left(R_{i}(1), \ldots \ldots \ldots \ldots \ldots, R_{i}(T)\right)^{\prime} \quad \text { is } \mathrm{T} \times 1 \quad \mathrm{i}=1,2, \ldots \ldots \ldots \ldots, \mathrm{N} \\
& \tilde{f}_{k}=\left(\tilde{f}_{k}(1), \ldots \ldots \ldots \ldots ., \tilde{f}_{k}(T)\right)^{\prime} \quad \text { is } \mathrm{T} \times 1 \quad \mathrm{k}=1,2, \ldots \ldots \ldots \ldots, \mathrm{K} \\
& \varepsilon_{i}=\left(\varepsilon_{i}(1), \ldots \ldots \ldots \ldots . ., \varepsilon_{i}(T)\right)^{\prime} \quad \text { is } \mathrm{T} \times 1 \quad \mathrm{i}=1,2, \ldots \ldots \ldots \ldots, \mathrm{N} \\
& B_{i}=\left(\beta_{i 1}, \ldots \ldots \ldots \ldots \ldots, \beta_{i k}\right)^{\prime} \\
& X(\lambda)=\left[\lambda_{1} l_{T}+\tilde{f}_{1}, \ldots \ldots \ldots, \lambda_{K} l_{T}+\tilde{f}_{K}\right] \quad \text { is } \mathrm{T} \times 1 \quad \mathrm{i}=1,2, \ldots \ldots \ldots \ldots, \mathrm{N}
\end{aligned}
$$

Stacking equation (3.2) for $\mathrm{N}$ securities yields

$$
R=\left[I_{N} \otimes X(\lambda)\right] B+\varepsilon
$$

Where $\mathrm{I}_{\mathrm{N}}$ is an identity matrix, and $\otimes$ is Kronecker product.

Provided that $\mathrm{T}$ and $\mathrm{N}$ are sufficiently large relative to $\mathrm{K}$ so that $\mathrm{NT}>\mathrm{NK}+\mathrm{K}+1$, Burmeister and McElroy [1985] propose to obtain NLSUR estimates of sensitivities and risk premia in the following steps:

1) estimate equation (3.1) using security-by-security OLS by replacing $\lambda_{\mathrm{k}}$ with a constant; 
2) use the residual vectors from step one to get an estimate of $\Sigma$ with the following formula:

$\hat{\Sigma}=\left[(1 / T) \hat{e}_{i}^{\prime} \hat{e}_{j}\right]$

where $\sum$ is true $\mathrm{N} \times \mathrm{N}$ covariance matrix of the error terms, $\hat{\Sigma}$ is an estimate of $\sum, \hat{e}_{i}^{\prime}$ is the transpose of residual vector with respect to security ' $i$ ', and $\hat{e}_{j}$ is the residual vector with respect to security ' $j$ '.

3) in step three, the consistent estimates of true assets' sensitivities and risk premia are obtained by minimising the residuals from stacked regression (3.3) the following expression :

$$
\min _{B, \lambda} \varepsilon^{\prime}\left(\hat{\Sigma} \otimes I_{T}\right) \varepsilon
$$

The NLSUR estimates can also be obtained through iterative algorithm. To estimate the factor risk premia and assets' sensitivities jointly through iterative algorithm. Burmeister and McElroy [1985, pp.274] propose to repeat the three steps outlined in section 2.3 and iterate until the system converges to its optimum value. The estimates obtained from iterative process i.e. ITNLSUR, are superior to simple NLSUR estimators because in addition to consistency of the NLSUR estimators, the ITNLSUR estimators are asymptotically efficient [Burmeister and McElroy, 1985, pp.274].

\subsection{ITNLSUR Estimation for Factor Risk Premia}

WinRats-32 is used in this study, to jointly estimate the factor risk premia ' $\lambda s$ ' and assets sensitivities ' $\beta$ s' through ITNLSUR [see Rats manual, section 14-172]. To obtain the risk premia and assets' sensitivities with ITNLSUR, we minimise the expression (3.4) and iterate until the system converges to its optimum value. For the iterative process i.e. to move from one point to the next, the procedure outlined in Berndt et a1.[1974] is applied [Rats manual, section 14-171]. For the iterative process to converge toward the optimum value of the function, we need to provide some starting values for $\beta s$ and $\lambda s$, and the better the initial values, the easier it is for the system to converge towards its optimum value. To obtain the initial values for $\beta$ s and $\lambda s$, first the sensitivity coefficients are obtained through security-by-security OLS regressions using unanticipated shocks as independent variables. Then these estimates of coefficients and the innovations in macro factors are used as inputs in equation (1.6) to obtain the initial values for the $\lambda \mathrm{s}$ [see, Lajeri and Dermine, 1999, section 5.1]. 
Finally, these $\beta$ s and $\lambda s$ are used as initial values in the iterative algorithm to jointly obtain the estimates risk prices associated with the pre-specified macroeconomic variables and assets' sensitivities from the system of sixty securities.

\subsection{The APT Pricing Restriction}

One advantage of using the non-linear joint estimation technique to obtain estimate of risk prices and assets' sensitivities is that “... this framework can be used to test rather than impose the non-linear, cross equation restrictions the APT places on a more general, unrestricted linear factor mode1 [Antoniou et a1., 1998, pp. 225]". The linear factor model with $\mathrm{k}$ factors can be described as:

$$
\rho_{i}=\alpha_{i}+\sum_{k=1}^{K} f_{k} \beta_{i k}+\varepsilon_{i}
$$

By comparing equation (4.1) and (1.7), it is obvious that the APT impose non-linear ${ }^{13}$ restrictions on the linear factor model, namely:

$$
\alpha_{i}=\sum_{k=1}^{K} \beta_{i k} \lambda_{k}
$$

The APT restriction (4.2) can be easily tested using a likelihood ratio test [see, for example, Priestley, 1996].

\subsection{Empirical Results}

The empirical results from the ITNLSUR estimation of the risk prices associated with the macroeconomic factors of Pakistan, are presented in Table 3.1. The t-ratios in Table 3.1 suggest that four macroeconomic factors carry a risk premium in the Pakistani stock market, these factors being unexpected inflation, exchange rate, trade balance, and oil prices. The $\chi^{2}$ value i.e. likelihood ratio test shows that the APT restrictions can be easily accepted at the $5 \%$ significance leve1.

\footnotetext{
${ }^{13}$ The restrictions are non-linear because $\lambda$ is unknown. See Burmeister and McElroy
} [1985, pp.273]. 
Table-3.1: Estimates of the Risk Premia carried by the significant factors

\begin{tabular}{lll}
\hline$\lambda_{1}$ (unexpected inflation) & $0.001801^{* *}$ & $(-2.430)$ \\
$\lambda_{2}$ (money supply) & 0.000350 & $(0.139)$ \\
$\lambda_{3}$ (exchange rates) & $0.000903^{* * *}$ & $(3.401)$ \\
$\lambda_{4}$ (term structure) & 0.001020 & $(0.305)$ \\
$\lambda_{5}$ (trade balance) & $0.001402^{* *}$ & $(1.968)$ \\
$\lambda_{6}$ (industrial production) & 0.004512 & $(0.023)$ \\
$\lambda_{7}$ (raw material) & 0.001282 & $(0.753)$ \\
$\lambda_{8}$ (oil prices) & $0.007640^{*}$ & $(1.708)$ \\
$\lambda_{9}$ (domestic credit) & 0.001021 & $(0.021)$ \\
APT Pricing Retriction & & \\
$\mathrm{H}_{\mathrm{o}}: \alpha_{9}=\sum_{k=1}^{K} \beta_{k} \lambda_{k} \mathrm{I}$ & $\chi^{2}(50)=54.231^{\#}$ & \\
\hline
\end{tabular}

Figures in parenthesis in the above table are t-ratios: ${ }^{*}$ significance at $10 \%$, $* *$ significance at $5 \%, * * *$ significance at $1 \%$. The statistic testing $\mathrm{H}_{\mathrm{o}}$ is a likelihood ratio test, distributed $\chi^{2}$ ( .) under null. Approximate $5 \%$ critical value is 83.61 .

\section{Conclusion}

In this paper, we have examined the risk-return relationship of the Pakistani stock market. The purpose of the study was to examine whether the APT has any empirical validity for the Pakistani stock market. Our results suggest that domestic macroeconomic factors - unexpected inflation, exchange rate, trade balance, and oil prices - are a source of systematic risk in the Pakistani stock market, and the APT pricing restrictions hold. These results can help corporate managers undertaking cost of capital calculations, domestic and international fund managers making investment decisions and, amongst others, individual investors who wish to assess the performance of managed funds. These results, however, do not suggest that the macroeconomic variables that are found to have significant risk premia in this paper are the only factors that carry systematic risk, but these results could be used as a benchmark to help the key market players in the Pakistani stock market upgrade their knowledge about the phenomenon of risk and return. 
72 The Lahore Journal of Economics, Vol.6, No.1

\section{References}

Antoniou, A., Garrett, I., and Priestley, R., 1998, "Macroeconomic Variables as Common Pervasive Risk Factors and the Empirical Content of the Arbitrage Pricing Theory”, Journal of Empirical Finance, Vo1. 5, pp. 221-240.

Berndt, E.K., Hall, B.H., Hall, R.E., and Hausman, J.A., 1974, "Estimation and Inference in Nonlinear Structural Models", Annals of Economic and Social Measurement, Vo1.3/4, pp.653-665.

Brown, S.J., and Otsuki, T., 1990, "Macroeconomic Factors and the Japanese Equity Markets: The CAPMD Project”, In Edwin J. Elton and Martin J. Gruber (eds), Japanese Capital Markets, Harper and Row, New York, N.Y.

Burmeister, E., and McElory, M.B., 1985, "Two Estimators for the APT Mode1 When Factors are Measured", The Economic Letters, Vo1. 19, pp. 271-275.

Burmeister, E., and McElroy, M.B., 1988, "Joint Estimation of Factor Sensitivities and Risk Premia for the Arbitrage Pricing Theory", Journal of Finance, Vol. 43, pp.721-733.

Chen, N., Roll, R., and Ross, S.A., 1986, "Economic Factors and the Stockmarket”, Journal of Business, Vo1. 58, pp.383-403

Chan, K.C., Chen, N., and Hsieh, D.A., 1985, "An Exploratory Investigation of the Firm Size Effect”, Journal of Financial Economics, Vol.14, pp.451-471.

Chamberlain, G., and Rothschild, M., 1983, "Arbitrage and mean variance analysis on large asset markets”, Econometrica, Vol.51, pp.1281-1304.

Chamberlain, G., 1983, "Funds, Factors, and Diversification in Arbitrage Pricing Model”, Econometrica, Vol. 51, pp.1305-1323.

Clare, A.C., and Thomas, S.H., 1994, "Macroeconomic Factors, the APT and the UK Stockmarket", Journal of Business, Finance and Accounting, Vo1. 21, 309-330.

Clare, A.C., Thomas, S.H., and Priestley, R., 1998, "Reports of Beta's Death are Premature: Evidence from the UK”, Journal of Banking and Finance, Vol. 22, pp. 1207-1229. 
Connor, G., and Korajczyk, R.A., 1995, "The Arbitrage Pricing Theory and Multifactor Models of Asset Returns”, Jarrow, R., Maksimovic, V. Ziemba, W. eds. , Finance Handbook, pp. 87-137.

Davidson, R. and MacKinnon, J.G., 1993, Estimation and Inference in Econometrics, Oxford University Press, Oxford.

Fama, E.F., 1981, "Stock Returns, Real Activity, Inflation and Money", American Economic Review, Vo1.71, pp.545-565.

Fama, E.F., and MacBeth, J.D. (1973), "Risk, Return and Equilibrium: Empirical Tests”, Journal of Political Economy, Vo1.81(3), pp.607-636.

Ferson, W.E., and Harvey, C.R., 1991, "The Variation of Economic Risk Premium”, Journal of Political Economy, pp. 385-415.

Friend, I., and Blume, M., 1970, "Measurement of Portfolio Performance Under Uncertainty”, American Economic Review, Vol. 60(4), pp. 561-575.

Gallant, A.R., 1975, “Seemingly Unrelated Non-linear Regressions”, Journal of Econometrics, Vol. 3, pp.35-50.

Gehr, A. Jr., 1978, "Some Tests of Arbitrage Pricing Theory", Journal of Midwest Finance Association, Vo1. 7, pp.91-106.

Greene, W.H., 2000, Econometric Analysis, Upper Saddle River, N.J.: Prentice Hall.

Hawking, Stephen, 1998, A Brief History of Time, BCA, London.

Lajeri, F., and Dermine, J., 1999, "Unexpected inflation and bank stock returns: The case of France 1977-1991", Journal of Banking \& Finance, Vol. 23, pp. 939-953.

Lintner, J., 1965, "The Valuation of Risk Assets and the Selection of Risky Investments in Stock Portfolios and Capital Budgets”, Review of Economics and Statistics, Vol.47, pp.13-37.

Lintner, J., 1976, “Inflation and Security Returns", Journal of Finance, Vo1. 30, pp.1259-280.

Litzenberger, R.H., and Ramaswamy, K., 1979, "The Effects of Personal Taxes and Dividends on Capital Asset Prices: Theory and Empirical Evidence”, Journal of Financial Economics, Vol. 7, pp.163-196. 
74 The Lahore Journal of Economics, Vol.6, No.1

Modigliani, F., and Cohn, R., 1979, "Inflation, Rational Valuation, and the Market”, Financial Analyst Journal, Vo1. 35, pp. 22-44.

Priestley, A.M., 1996, "The Arbitrage Pricing Theory, Macroeconomic and Financial Factors, and Expectation Generating Processes”, Journal of Banking and Finance, Vo1.20, pp.869-890.

Priestley, R., and Clare, A.D., 1998, "Risk factors in the Malaysian stock market”, Pacific-Basin Finance Journal, Vo1.6, pp.103-114.

RATS User's Manual, Version 4, 1996 by Doan T. A., Evanston, I11:Estima.

Roll, R., 1977, “A Critique of the Asset Pricing Theory's Tests: Part I: On Past and Potential Testability of the Theory", Journal of Financial Economics, Vol. 4, pp.129-176.

Rol1, R., and Ross, S.A., 1980, "An Empirical Investigation of the Arbitrage Pricing Theory”, Journal of Finance, Vol. (35), pp. 1073-1103.

Ross, S.A., 1976, “The Arbitrage Theory of Capital Asset Pricing”, Journal of Economic Theory, Vol. 13, pp. 341-360.

Shanken, J., 1992, "On the Estimation of Beta-Pricing Models", The Review of Financial Studies, Vo1. 5, pp.1-33.

Shanken, J., and Weinstein, M.I., 1990, "Macroeconomic Variables and Asset Pricing: Estimation and Tests", Working Paper, University of Rochester, Rochester, N.Y.

Sharpe, W.F.,1964, "Capital Asset Prices: A Theory of Market Equilibrium Under Conditions of Risk”, Journal of Finance, Vo1. 19, pp.425-442.

Sims, C.A., 1980, "Macroeconomics and Reality", Econometrica, Vo1.48, pp.1-49.

Trzcinka, C., 1986, "On the number of factors in the arbitrage pricing model”, Journal of Finance, Vo1. 41, pp.347-368.

Warga, A., 1989, "Experimental Design in Tests of Linear Factor Model", Journal of Business Economics and Statistics, Vo1. 7, pp.191-198.

Zellner, A., 1962, "An efficient method of estimating seemingly unrelated regression equations and tests for aggregation bias”, Journal of the American Statistical Association, Vo1.57, pp. 500-509. 